\title{
Effects of saline extract of ovine hydatid Cyst scoleces in Sheep
}

\author{
Blockade of responses by compound $48 / 80^{(*)}$
}

\author{
by M. TABATABAI, M. VESSAL and N. COHANIM \\ Departments of Physiology and Biochemistry, School of Medicine, \\ Shiraz University, Shiraz, Iran.
}

SUMMARY. The effects of intravenous administration of the saline extract of the ovine hydatid cyst scoleces on the cardiovascular and respiratory systems were studied in sodium pentobarbital-anesthesized sheep. Scoleces were obtained from the lung hydatid cysts of freshly slaughtered sheep, sonicated in physiologic saline and centrifuged to recover the extract in the supernatant fluid.

Administration of $1.4 \mathrm{ml}$ of the saline extract resulted in hypotension, shallow rapid respiration, slight elevation of the central venous pressure and transient electrocardio. graphic changes.

Pretreatment of the animals with atropine, $1 \mathrm{mg} / \mathrm{kg}$ S.C., or with the antihistamine antazoline, $5 \mathrm{mg} / \mathrm{kg} I . V$., dit not block the responses to the saline extract of the hydatid cyst scoleces.

Pretreatment with compound 48/80, a histamine releaser, abolished the reactions to the administration of the scoleces extract.

It is concluded that ovine hydatid scoleces extract has profound cardiovascular and respiratory effects, and that histamine release seems to be involved in the induction of responses to the extract. Iran.

(*) This investigation was supported, in part, by a grant from the Shiraz University, Shiraz,

Accepté le 26 février 1980. 


\section{Effet d'extrait salin de scolex de kystes hydatiques ovins sur le mouton.}

RESUME. Les effets de l'injection intra-veineuse d'extrait salin de scolex de kystes hydatiques ovins sur les systèmes cardiovasculaire et respiratoire ont été étudiés chez des moutons anesthésiés au pentobarbital sodique.

Les scolex de kystes hydatiques pulmonaires de moutons fraîchement sacrifiés ont été soniqués dans du sérum physiologique et centrifugés afin de recueillir l'extrait contenu dans le supernatant.

L'administration de 1 à $4 \mathrm{ml}$ d'extrait salin a entrainé un effondrement de la tension artérielle, une accélération du rythme respiratoire, une légère élévation de la pression veineuse centrale ainsi que des modifications transitoires de l'électrocardiogramme.

Le prétraitement des animaux avec de l'atropine $(1 \mathrm{mg} / \mathrm{kg})$ injectée par voie souscutanée ou avec l'antihistamine antazoline $(5 \mathrm{mg} / \mathrm{kg})$ injectée par voie intra-veineuse n'a pas aboli la réaction à l'administration d'extrait salin de scolex de kystes hydatiques. Le prétraitement des animaux avec le produit $48 / 80$, qui induit la libération d'histamine, supprime les réactions produites par l'injection d'extrait de scolex.

En conclusion, l'injection d'extrait de scolex hydatiques ovins entraîne des réactions cardiovasculaires et respiratoires sérieuses et la libération d'histamine semble être liée à l'induction de ces réponses.

\section{Introduction}

Rupture of the hydatid cyst in man may cause dyspnea, cyanosis, vomiting, diarrhea, circulatory shock and sudden death $(1,3,5)$. Experimentally, administration of the ovine hydatid fluid to laboratory animals such as cats, dogs and sheep produces hypotension, cardiac arhythmia, rapid respiration and death (6-10). Within the hydatid cyst, there are scoleces whose products contribute to the hydatid fluid contents.

In the present investigation, the effects of the saline extract of the hydatid scoleces on the cardiovascular and respiratory systems of sheep were studied. The responses were blocked by pretreatment of the animals with compound $48 / 80$, indicating the role of histamine in the mediation of the reactions to the extract.

\section{Materials and methods}

Thirty sheep, weighing $23-28 \mathrm{~kg}$, were anesthetized with sodium pentobarbital $25 \mathrm{mg} / \mathrm{kg} \mathrm{I.V}$. Arterial blood pressure (ABP), central venous pressure (CVP), electrocardiogram (ECG) and respiration were recorded on a Grass polygraph (Grass Instrument Co., Quincy, Mass.). All the intravenous injections were administered through the catheter used for the measurement of the CVP. 
The animals could be tested more than once, each test 48 hours or more apart.

At the beginning of each test, the baseline ABP, respiration and ECG were checked to ensure that the sheep has recovered from the previous operation and test.

At the end of the tests, the animals were killed by giving lethal doses of the anesthetic, and the liver and lungs were grossly examined for the presence of hydatid cysts.

Preparation of SALine scolex EXtract: Saline scolex extract was prepared by sonicating the scoleces ( 2 grams in $20 \mathrm{ml} 0.9 \%$ sodium chloride solution) for 30 minutes in a Bronswill sonic oscillator. The scoleces were obtained from the lung hydatid cysts of sheep freshly slaughtered. The sonicated solution was centrifuged and the supernatant fluid, containing the extract was removed and mixed with $0.9 \%$ sodium chloride solution. The final saline extract contained $400 \mathrm{mg}$ protein per $100 \mathrm{ml}$. The animals received $1-4 \mathrm{ml}$ of this solution intravenously. Physiologic sodium chloride solution $(0.9 \%)$ was used as the control solution.

Pretreatment With atropine, antazoline and compound 48/80: Five sheep with cardiovascular and respiratory responses to scolex extract during the first test were pretreated with atropine, $1 \mathrm{mg} / \mathrm{kg}$ subcutaneously, during the second test 20 minutes before administration of the scolex extract. The anticholinergic effect of atropine was tested against intravenous injection of acetylocholine, $10 \mu \mathrm{g} / \mathrm{kg}$.

Five other sheep which developed respiratory and cardiovascular responses to the scolex extract during the first test were pretreated with the antihistamine antazoline, $5 \mathrm{mg} / \mathrm{kg} \mathrm{I.V.,} \mathrm{2-5} \mathrm{minutes} \mathrm{before} \mathrm{injection} \mathrm{of} \mathrm{scolex} \mathrm{extract} \mathrm{during} \mathrm{the} \mathrm{second}$ test. The antihistaminic effect of antazoline was assessed against intravenous injection of histamine, $5 \mu \mathrm{g} / \mathrm{kg}$ I.V.

Five other sheep with cardiovascular and respiratory responses to the scolex extract during the first test were given compound 48/80, a histamine releaser (4), during the second test before administration of the extract. The amount given was $0.05 \mathrm{mg} / \mathrm{kg}$ I.V. The response to the compound was a transient precipitous fall in the $\mathrm{ABP}$ and shallow rapid respiration. The compound was repeated every 30 minutes until there was no more response to the compound, at which time the animal was considered histamine depleted.

\section{Results}

CARDiovascular RESPONSES: Administration of 1-4 ml extract solution caused diminution of the ABP in 27 sheep ( $90 \%$ ), of which six (20\% of the total) died. Among the surviving ones, the mean ABP of $108 \mathrm{~mm} \mathrm{Hg}$ decreased to $60 \mathrm{~mm} \mathrm{Hg}$, the difference being statistically significant $(P<0.01)$. ABP returned to the preinjection value in 1-5 minutes. Subsequent injections of equal volumes of the same extract solution during the same test evoked either a lesser hypotensive response 
or none at all (fig. 1). However, 48 hours or more later, during the second test, the magnitude of the hypotensive response to the extract was equal to or more than that observed during the first test.

Other cardiovascular responses were slight elevation of the CVP $\left(1-3 \mathrm{~cm} \mathrm{H}_{2} \mathrm{O}\right)$, frequent decrease or occasional increase in the heart rate and ECG changes. The latter consisted of flattening or inversion of the $\mathrm{T}$ wave, premature atrial and/or ventricular contractions, and ST segment depression. The ECG changes were transient and disappeared 2-3 minutes after return of the ABP to normal.

RESPIRATORY RESPONSES: All the 27 sheep with cardiovascular responses to the scolex extract developed respiratory changes as well. In 20 sheep, respiration became fast and shallow (fig. 1) and in 7, fast and slightly deep (fig. 2). It took 10 to 15 minutes for respiration to return to the preinjection state. Cccasionally there were short periods of apnea (10-30 seconds) interposed between the tachypneic phases.

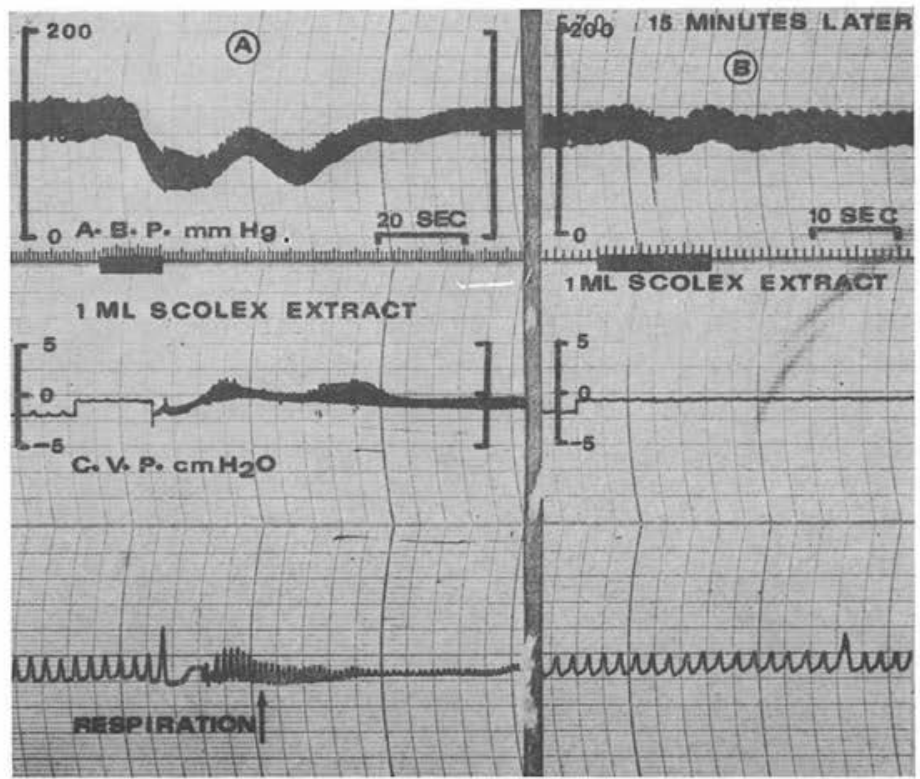

Fig. 1. Effect of intravenous injection of $1 \mathrm{ml}$ of the saline extract of the hydatid cyst scoleces on the arterial blood pressure (ABP), central venous pressure (CVP) and respiration. In Panel A (left side), the ABP dropped, the CVP slightly rose and respiration became shallow and fast. Fifteen minutes later (Panel B, right side), on second injection of the extract, only slight change in $\mathrm{ABP}$ developed while CVP and respiration did not change. 
Among the animals which died after the scolex extract injection, respiration gradually slowed down and finally ceased. Artificial respiration by pressing upon the chest failed to resuscitate them.

EfFect of Pretreatment with atropine: Pretreatment with atropine $(1 \mathrm{mg} / \mathrm{kg}$ S.C.) did not abolish the responses to the scolex extract (fig. 2), although it blocked the hypotensive effect of the intravenous injection of $10 \mu \mathrm{g} / \mathrm{kg}$ acetylcholine.

EFFect of pretreatment With antazoline: Pretreatment with the antihistamine antazoline ( $5 \mathrm{mg} / \mathrm{kg} \mathrm{I.V.)} \mathrm{did} \mathrm{not} \mathrm{prevent} \mathrm{the} \mathrm{reactions} \mathrm{to} \mathrm{the} \mathrm{extract} \mathrm{(fig.} \mathrm{3),} \mathrm{though}$ it prevented the cardiovascular and respiratory responses to intravenous injection of $5 \mu \mathrm{g} / \mathrm{kg}$ histamine.

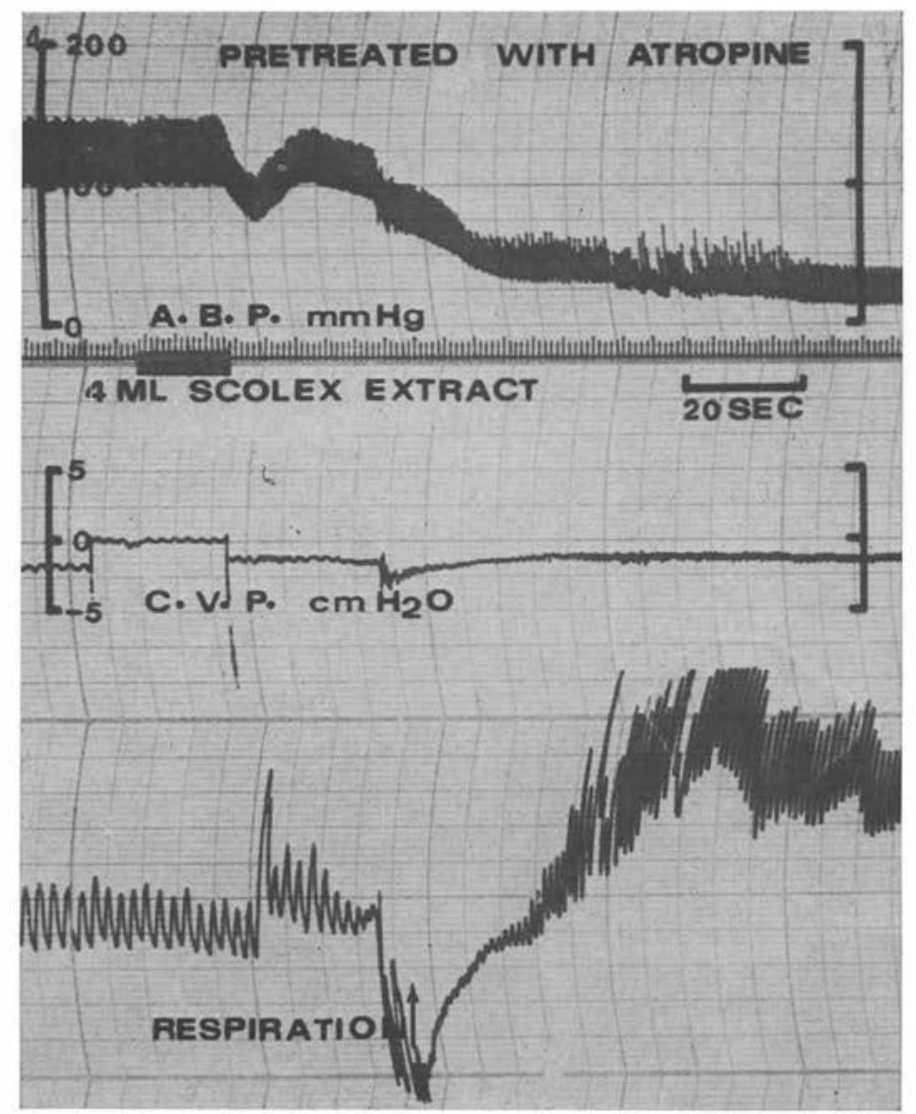

Fig. 2. Pretreatment with atropine fails to prevent responses to hydatid scoleces extract. 


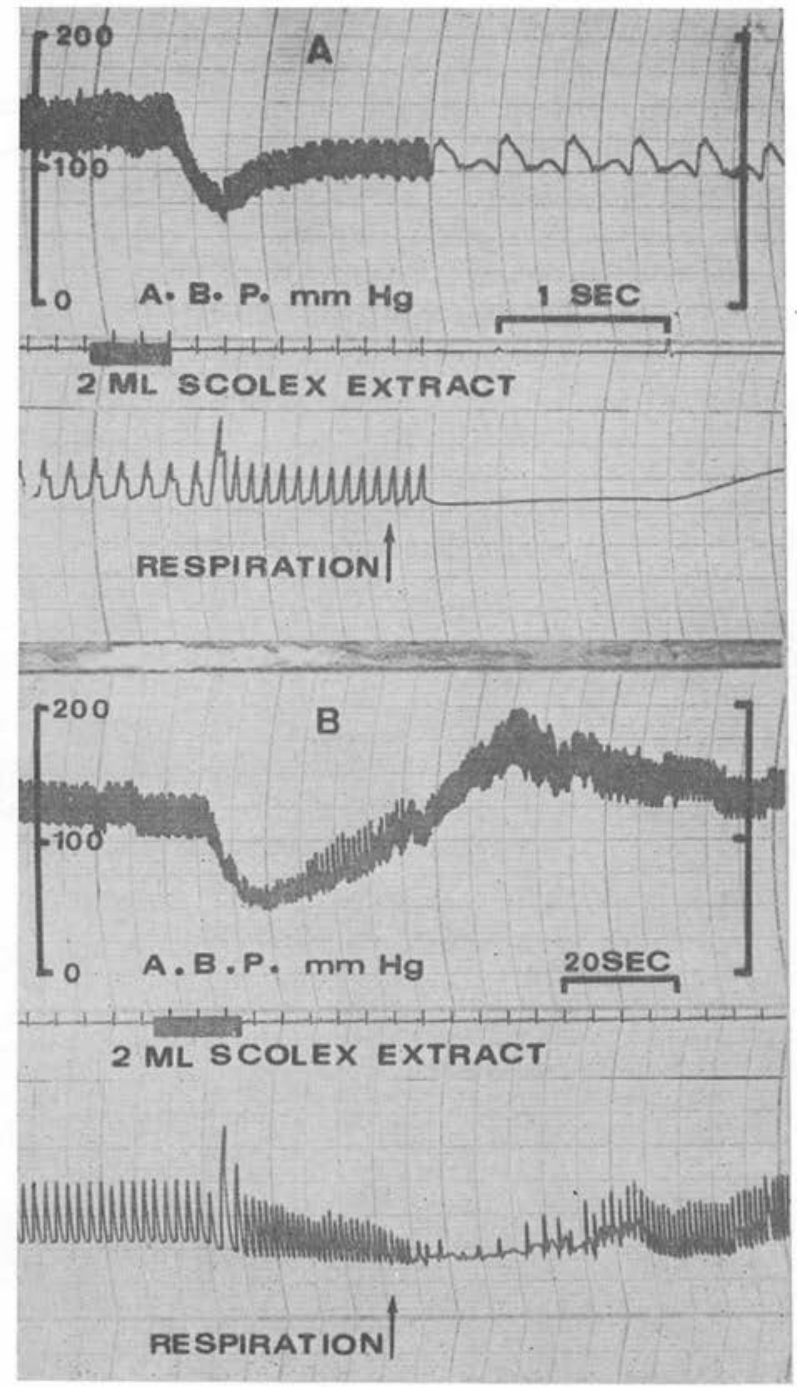

Fig. 3. Arterial blood pressure (ABP) and respiratory responses to scoleces extract before (Panel A) and after (Panel B) treatment with the antihistamine antazoline. The duration between the two tests was 48 hours. Note that antazoline did not abolish the responses. 
EFFECT OF PRETREATMENT WITH COMPOUND 48/80: Compound 48/80 successfully blocked the reactions to the scolex extract solution (fig. 4). Even as much as $8 \mathrm{ml}$ extract solution failed to evoke any response in the compound-pretreated group.

Gross postmortem examination of the liver and lungs dit not show any hydatid cyst.

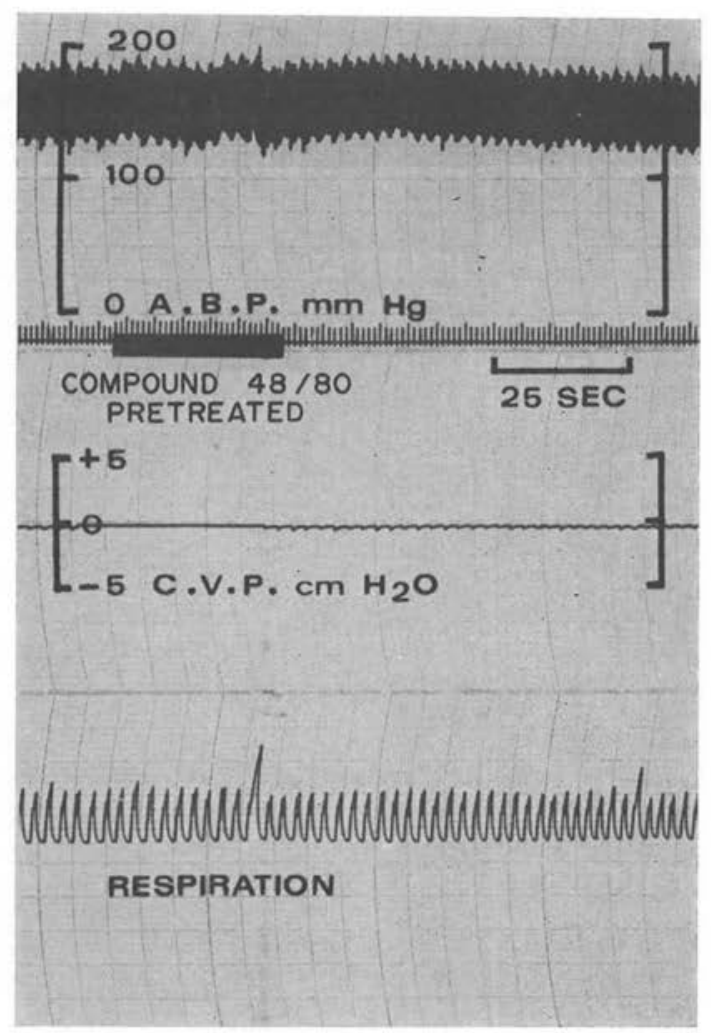

Fig. 4. Effect of compound $48 / 80$ on the blockade of the reactions to $4 \mathrm{ml}$ hydatid scoleces extract during the second test. During the first test (not shown here) 48 hours earlier, the sheep developed hypotension and shallow rapid respiration to scoleces extract injection.

\section{Discussion}

The saline extract of the ovine hydatid cyst scoleces has pronounced cardiovascular and respiratory effects in sheep. The elicited responses are similar to those brought about by the hydatid cyst fluid administration to some laboratory animals (7-10). 
Atropine did not block the reactions to the extract, suggesting that the extract dit not contain acetylcholine or other parasympathomimetic agents.

Compound $48 / 80$, a histamine releaser (4) abolished the reactions to the scolex extract, showing that the action of the extract was through the release of histamine from the tissues in the body. In support of this conclusion is the observation that subsequent injections of the extract during the same test produced a lesser hypotensive response or none at all (fig. 1), indicating that the extract decreased or depleted the body contents of histamine on the first injection, so that during the second injection less or no histamine was released. Histamine release by the extract, however, may be a direct effect or it may be brought about by antigen-antibody reaction.

If the responses to the extract are due to the release of histamine, the question arises as to why the antihistamine antazoline failed to prevent the responses to the extract. It is conceivable to assume that the amount of histamine released was more than what could be blocked by the amount of antazoline administered.

In line with the results of the present investigation, we have shown that the responses to hydatid cyst fluid administration cannot be blocked by pretreatment with atropine or antihistamines $(9,10)$, but can be prevented by pretreatment with compound 48/80 (unpublished data).

\section{References}

1. Brown H.W.: Chapter on "Diseases caused by metazoa " in P. B. Beeson and W. McDermott, «Cecil and Loeb Textbook of Medicine», pp. 421-423. W. B. Saunders Company, Philadelphia and London, 1963.

2. Dew H.R. : Hydatid Disease: Its Pathology, Diagnosis and Treatment. Australian Medical Publishing Company, Sydney, 1928.

3. Dibello R., Menendez H. : Intracardiac rupture of hydatid cyst of the heart. A study based on three personal observations and 101 cases in the world literature. Circulation, 1963, 27, 366-374.

4. Douglas W. W.: Histamine and Antihistamines, pp. 590-615. In Goodman L.S., Gilman A., Eds.: The Pharmacological Basis of Therapeutics. Fifth edition, Macmillan Publishing Co., New York, 1975.

5. Handjani A.M., Farpour A., Mechanic K., Haghighat A., Dutz W.: Cardiovascular echinococcosis. Am. J. Surg., 1969, 117, 666-670.

6. Rocha e Silva M., Grana A. : Shock produced in dogs by hydatid fluid. Am. J. Physiol., 1945, 143, 306-313.

7. Tabatabai M., Boroomand K., Gettner S. : Respiratory and cardiovascular responses resulting from intravenous injection of sheep hydatid cyst fluid to dogs. Exp. Parasitol., 1973, 34, 12-21.

8. Tabatabai M., Etemadi A. A., Cohanim N.: Shock induced in cats by intravenous injection of ovine hydatid cyst fluid. Pahlavi Med. J., 1973, 4, 398-416.

9. Tabatabai M., Ismaili M. H., Nazarian I., Daneshbod K.: Pathophysiological changes resulting from intravenous injection of ovine hydatid cyst fluid to sheep. Br. J. Exp. Pathol., 1974, 55, 33-37.

10. Tabatabai M., Ismaili M. H., Sami M., Fardin R., Kadivar R. : Effect of ovine hydatid cyst fluid on the cardiovascular and respiratory systems in sheep. Ain. Parasitol. Hum. Comp., $1975,50,7-15$. 